\title{
Neutrophil to Lymphocyte Ratio Predicts Short-Term Functional Outcome in Acute Ischemic Stroke
}

\author{
Meyung Kug Kim, Jin Hyung Lee, Bong Goo Yoo* \\ Department of Neurology, Kosin University College of Medicine, Busan, South Korea
}

*Corresponding Author: Bong Goo Yoo, Department of Neurology, Kosin University College of Medicine, Busan, South Korea, Email: ybg99@naver.com

\begin{abstract}
The neutrophil to lymphocyte ratio $(N L R)$ has been proposed to predict clinical outcome in cardiovascular diseases. We assessed the significance of the NLR as a predictor of outcome in acute ischemic stroke (AIS) patients.

We retrospectively analyzed the clinical data in 340 consecutive patients with AIS. The NLR was calculated from the differential counts by dividing the neutrophil number by the lymphocyte number. Outcome was measured as a 3-month modified Rankin Scale ( $m R S)$ score. Multivariate logistic regression analysis was used to assess the association among the clinical, inflammatory, and serological parameters.

The NLR was significantly higher in the poor outcome group $(P<0.05)$. The cut-off value of the NLR for the prediction of poor outcome was 2.135 (sensitivity 0.864, specificity 0.533). Multivariate logistic regression analysis demonstrated that age $\geq 65$ years (OR 10.2; $95 \%$ CI 3.31-31.21, $P<0.001)$, presence of diabetes $(O R$ 3.3; 95\% CI 1.36-8.18, P=0.008), NIHSS score $\geq 4$ (OR 26.4; 95\% CI 9.81-71.15, P<0.001), hs-CRP level (OR 1.2; 95\% CI 1.01-1.34, P=0.041), and NLR $\geq 2.135$ (OR 9.2; 95\% CI 3.18-26.4, P<0.001) were independently associated with poor outcome.
\end{abstract}

The NLR is a useful marker for short-term outcome in AIS and may have a role in risk stratification for predicting poor outcome.

Keywords: Neutrophils, Lymphocytes, Stroke, Prognosis

\section{INTRODUCTION}

Ischemic stroke is a major cause of disability and mortality worldwide [1]. The mortality rate of stroke has steadily decreased in South Korea, over the last 10 years, but was still 51.1 per 100,000 people in 2012, making it the third leading cause of death [1].

It is well established that inflammation plays an important role in various atherosclerotic disorders [2, 3]. Elevated blood inflammatory markers such as high sensitivity C-reactive protein (hs-CRP) have been shown to be independent risk factors for cardiovascular disease and ischemic stroke [2, 3]. Recently, there have been reports of leukocytes having a similar role in ischemic events $[4,5]$.

Inflammatory cascade following acute ischemic stroke (AIS) is an important pathological process in damaged brain tissue $[4,5]$. The inflammatory process in AIS involves cytokines and chemokines released from ischemic tissues, promoting the accumulation of leukocytes to the ischemic areas [5, 6]. Among circulating leukocytes, neutrophils have been regarded as crucial mediators of ischemic injury [6-8]. Accumulated neutrophils release free oxygen radicals, various inflammatory cytokines, and neurotoxic substances, all of which cause cellular necrosis and apoptosis in ischemic tissues [9]. Lymphocytes, a type of leukocyte, are also known to be involved in inflammatory responses to AIS [10]. Low lymphocyte counts increase sympathetic activity and baseline cortisol levels, which can cause an increase in the production of inflammatory cytokines that aggravate ischemic injury [11]. Therefore, increased total white blood cell (WBC) and leukocyte counts, and reduced lymphocyte counts are associated with poor outcomes in various cardiovascular diseases [10,11]. Theoretically, anti-inflammatory therapy may be beneficial in stroke management and has been shown to be effective in some experimental models [12, 13]. However, anti-neutrophil 
therapy has not been shown to be effective in clinical studies of AIS [14, 15].

The neutrophil to lymphocyte ratio (NLR) is a simple inflammatory marker that can be quickly calculated from the differential WBC count and that is an indicator of systemic inflammation [16]. An increase in the NLR has been shown to increase in-hospital mortality and morbidity in patients with acute coronary syndrome [17]. Recent studies have shown that the NLR provides a reliable inflammatory index that can be used for prognostic stratification in cardiovascular events [17-23]. However, the effects of the NLR on short-term functional outcome in AIS are still uncertain and few studies have been conducted [24].

Herein, we assessed the significance of the NLR as a predictor of short-term functional outcome in patients with AIS.

\section{Materials ANd Methods}

\subsection{Study Population}

We retrospectively analyzed 878 patients with AIS over the age of 18 years who were admitted to the department of neurology at the Kosin University College of Medicine within 3 days of AIS onset between July 2013 and March 2016. The diagnosis of AIS was determined by medical history, neurologic symptoms and signs, and neuroimaging. Exclusion criteria for the patients were as follows: (1) patients who were admitted to the hospital >3 days after stroke; (2) patients with a history of infection within 1 week of stroke onset or within 72 hours after admission; (3) patients with hematologic disorders or malignancies; (4) patients taking immunosuppressants or steroids; (5) patients with a history of recent stroke (i.e., past 6 months) and/or pre-stroke disability; (6) patients with severe pulmonary disease or chronic renal failure with dialysis; and (7) patients with intracerebral hemorrhage. Fourteen patients were further excluded due to loss of follow up at 3 months. A total of 340 patients who met the eligibility criteria were included in the study protocol. We retrospectively analyzed patients' clinical characteristics, laboratory parameters, NLRs, and 3-month follow-up modified Rankin Scale (mRS) scores [25].

\subsection{Clinical Data and Short-Term Functional Outcome}

The archived records from the hospital' $\mathrm{s}$ electronic record system were used to obtain the demographics (age, gender, and body mass index); the clinical characteristics, including stroke risk factors (hypertension, diabetes mellitus, hyperlipidemia, atrial fibrillation (AF), smoking and alcohol consumption); laboratory findings; and National Institutes of Health Stroke Scale (NIHSS) score on admission of the 340 patients who met the eligibility criteria [26]. Hypertension was defined as a systolic blood pressure (SBP) $\geq 140 \mathrm{mmHg}$, or a diastolic blood pressure (DBP) $\geq 90 \mathrm{mmHg}$, previous use of antihypertensive medication, or a history of diagnosed hypertension. Diabetes was defined as fasting blood glucose $\geq 126 \mathrm{mg} / \mathrm{dL}$, nonfasting glucose $\geq 200 \mathrm{mg} / \mathrm{dL}$, previous use of ant diabetic medications, or a previously established diagnosis. Hyperlipidemia was diagnosed on either fasting total cholesterol (TC) $\geq 240 \mathrm{mg} / \mathrm{dL}$, low-density lipoprotein (LDL) cholesterol $\geq 160$ $\mathrm{mg} / \mathrm{dL}$ or use of lipid lowering medication. A history of AF was defined as AF recorded at the time of the 12-lead electrocardiogram, 24-hours Holter monitoring, cardiac monitoring in the stroke unit, or a previously known episode of AF. A history of coronary artery disease was defined as a previously known episode of angina or myocardial infarction. A history of congestive heart failure was defined according to the Framingham heart failure diagnostic criteria [27]. Smoking within the past a month or alcohol consumption $>2$ times/month prior to admission were classified as present smoking or alcohol history, respectively.

A complete blood count analysis was performed on admission using peripheral venous blood samples collected in a calcium ethylene diaminetetraacetic acid (EDTA) tube. Blood counts were analyzed using an autoanalyzer (Unicel $^{\mathbb{R}}$ DxH $^{\mathrm{TM}} 800$ Coulter Cellular Analysis System, Beckman Coulter, Miami, Florida). The NLR was calculated as the ratio of neutrophils to lymphocytes in peripheral blood samples.

Brain magnetic resonance imaging (MRI) was performed on all patients. Outcome was measured using the mRS 3-months post-AIS. Good functional outcome was defined as an $\mathrm{mRS}$ of 0-2 points, whereas poor outcome was defined as an $\mathrm{mRS}>2$ points.

\subsection{Statistical Analysis}

Continuous variables are presented as mean \pm standard deviation. Categorical variables are presented as frequency and percentage. 
Differences between the good and poor outcome groups were analyzed through Chi-square tests, Student's t-tests, and Fishers exact tests. Logistic regression analysis was performed on odds ratios and $95 \%$ confidence intervals. The NLR cut-off value was analyzed through a receiver operating characteristic (ROC) curve. Multiple logistic regression analysis was performed to adjust for variables affecting outcome. Data were analyzed using Statistical Package for the Social Sciences (SPSS Inc., Chicago, IL, USA) version 22.0 software and the $P$-value was set at a significance level of 0.05 .

\section{Results}

\subsection{Baseline Characteristics}

Baseline characteristics of the 340 patients are shown in Table 1. The mean age of patients with AIS was $67.0 \pm 12.3$ years and $111(32.6 \%)$ were female. Two hundred twenty-five (66.2\%) of the patients had hypertension, $112(32.9 \%)$ had diabetes, $84(24.7 \%)$ had hyperlipidemia, 55 (16.2\%) had AF, 136 (40.0\%) were smokers, and $114(33.5 \%)$ consumed alcohol. The mean WBC count was $8,160 \pm 2,990 / \mu \mathrm{L}$ and the NLR mean was $3.47 \pm 4.5$. The mean NIHSS score on admission was $4.1 \pm 4.7$.

Table1. Baseline demographics and clinical characteristics of acute ischemic stroke patients according to outcome.

\begin{tabular}{|c|c|c|c|c|}
\hline Clinical parameter & All $(n=340)$ & $\begin{array}{l}\text { Good outcome } \\
\operatorname{mRS} \leq 2(n=274)\end{array}$ & $\begin{array}{l}\text { Poor outcome } \\
\mathrm{mRS}>2(\mathrm{n}=66)\end{array}$ & $P$-value \\
\hline Mean age (years) & $67 \pm 12.3$ & $64.2 \pm 11.6$ & $76.5 \pm 9.6$ & $<0.001$ \\
\hline Females, $\mathrm{n}(\%)$ & $111(32.6)$ & $77(28.1)$ & $34(51.5)$ & 0.012 \\
\hline Hypertension, $\mathrm{n}(\%)$ & $225(66.2)$ & $167(60.9)$ & $58(87.9)$ & 0.023 \\
\hline Diabetes, $\mathrm{n}(\%)$ & $112(32.9)$ & $79(28.8)$ & $33(50)$ & 0.031 \\
\hline Hyperlipidemia, n(\%) & $84(24.7)$ & $64(23.4)$ & $20(30.3)$ & 0.785 \\
\hline $\mathrm{CAD}, \mathrm{n}(\%)$ & $26(7.6)$ & $14(5.0)$ & $12(18.2)$ & 0.003 \\
\hline $\mathrm{CHF}, \mathrm{n}(\%)$ & $13(3.8)$ & $5(1.8)$ & $8(12.1)$ & 0.001 \\
\hline Atrial fibrillation, $\mathrm{n}(\%)$ & $55(16.2)$ & $26(9.5)$ & $29(43.9)$ & $<0.001$ \\
\hline Smokers, $\mathrm{n}(\%)$ & $136(40.0)$ & $113(41.2)$ & $23(34.8)$ & 0.024 \\
\hline Alcohol consumption, $\mathrm{n}(\%)$ & $114(33.5)$ & $100(36.5)$ & $14(21.2)$ & 0.002 \\
\hline Systolic BP (mmHg) & $158.9 \pm 27.9$ & $158.9 \pm 28.4$ & $158.9 \pm 26.6$ & 0.999 \\
\hline Diastolic BP (mmHg) & $88.7 \pm 17$ & $88.9 \pm 16.2$ & $88 \pm 19.6$ & 0.751 \\
\hline Heart rate $(/ \mathrm{min})$ & $79.3 \pm 17.3$ & $77.9 \pm 15.8$ & $84.2 \pm 21.1$ & 0.026 \\
\hline BMI $\left(\mathrm{kg} / \mathrm{m}^{2}\right)$ & $24 \pm 3.3$ & $24.1 \pm 3.17$ & $23.4 \pm 3.61$ & 0.193 \\
\hline $\mathrm{WBC}\left(10^{\wedge} 3 / \mu \mathrm{L}\right)$ & $8.16 \pm 2.99$ & $7.82 \pm 2.66$ & $9.55 \pm 3.82$ & 0.001 \\
\hline NLR & $3.47 \pm 4.5$ & $2.74 \pm 2.28$ & $6.51 \pm 8.5$ & $<0.001$ \\
\hline Hemoglobin $(\mathrm{g} / \mathrm{dL})$ & $13.66 \pm 1.79$ & $13.76 \pm 1.74$ & $13.24 \pm 1.93$ & 0.034 \\
\hline Platelet count $\left(10^{\wedge} 3 / \mu \mathrm{L}\right)$ & $221.7 \pm 68.1$ & $226.4 \pm 69.8$ & $202.4 \pm 57.1$ & 0.010 \\
\hline Total cholesterol (mg/dL) & $191.8 \pm 45.5$ & $191.1 \pm 42.9$ & $194.1 \pm 53.5$ & 0.679 \\
\hline $\mathrm{HDL}(\mathrm{mg} / \mathrm{dL})$ & $48.1 \pm 14.6$ & $47.7 \pm 13.9$ & $49.4 \pm 16.9$ & 0.434 \\
\hline Triglycerides (mg/dL) & $149.9 \pm 95.9$ & $156.7 \pm 101.3$ & $126.9 \pm 70.8$ & 0.008 \\
\hline $\mathrm{LDL}(\mathrm{mg} / \mathrm{dL})$ & $114.2 \pm 41.1$ & $114.2 \pm 39.5$ & $114.4 \pm 46.6$ & 0.969 \\
\hline
\end{tabular}

\subsection{Comparison Between Good and Poor Outcome Groups}

The good and poor outcome groups consisted of 274 and 66 patients, respectively. The good outcome group consisted of more male patients compared to the poor outcome group (71.9\% vs. $48.5 \%$, respectively, $P=0.012$ ). The mean age of the good outcome group was lower than the poor outcome group $(64.2 \pm 11.6$ vs. $76.5 \pm 9.6$ years, respectively, $P<0.001)$. In the poor outcome group, hypertension, diabetes, coronary artery disease, congestive heart failure and $\mathrm{AF}$ were significantly higher in prevalence than the good outcome group, but the rates of smoking and alcohol consumption were higher in the good outcome group. There was no significant difference in SBP, DBP, or body mass index between groups. Heart rate was more rapid in the poor outcome group $(P=0.026)$. The NIHSS at admission was $2.3 \pm 2.3$ in the good outcome group and 10.0 \pm 5.9 in the poor outcome group $(P<0.001)$. In the laboratory findings, WBC count, hs-CRP, creatine kinase-MB (CK-MB), and D-dimer were significantly higher in the poor outcome group than the good outcome group $(P<0.05)$. The NLR was significantly higher in the poor outcome group than the good outcome group $(6.51 \pm 8.5$ vs. $2.74 \pm 2.28$, respectively, $P<0.001)$ (Table 1$)$. 


\begin{tabular}{|l|c|c|c|c|}
\hline hs-CRP $(\mathrm{mg} / \mathrm{dL})$ & $0.83 \pm 2.42$ & $0.55 \pm 1.69$ & $1.75 \pm 3.91$ & 0.021 \\
\hline Homocysteine $(\mu \mathrm{Mol} / \mathrm{L})$ & $13.63 \pm 7.38$ & $13.89 \pm 7.78$ & $12.74 \pm 5.81$ & 0.330 \\
\hline CK-MB $(\mathrm{U} / \mathrm{L})$ & $2.89 \pm 3.35$ & $2.48 \pm 2.50$ & $4.24 \pm 5.07$ & 0.008 \\
\hline D-dimer $(\mathrm{mg} / \mathrm{L})$ & $0.83 \pm 2.00$ & $0.53 \pm 1.04$ & $1.89 \pm 3.59$ & 0.005 \\
\hline NIHSS on admission & $4.1 \pm 4.7$ & $2.3 \pm 2.3$ & $1.0 \pm 5.9$ & $<0.001$ \\
\hline
\end{tabular}

CAD; coronary artery disease, CHF; congestive heart Failure, BP; blood pressure, BMI; body mass index, $W B C$; white blood cell, NLR; neutrophil to lymphocyte ratio, HDL; high-density lipoprotein, LDL; low-density lipoprotein, hs-CRP; high sensitivity $C$-reactive protein, $C K-M B ;$ creatine kinase-MB, NIHSS; National Institutes of Health Stroke Scale, mRS; modified Rankin Scale. P-values were assessed using Student's t-test, Chi-square, or Fishes exact test.

\subsection{Cut-Off Values for the Prediction of Poor Outcome}

In the ROC curve analysis, the optimal cut-off outcome was 2.135 , with a sensitivity of $86.4 \%$ and a specificity of $53.3 \%$ (area under the curve: $0.739,95 \%$ CI $0.673-0.805$ ) (Fig. 1).

value of the NLR for prediction of poor

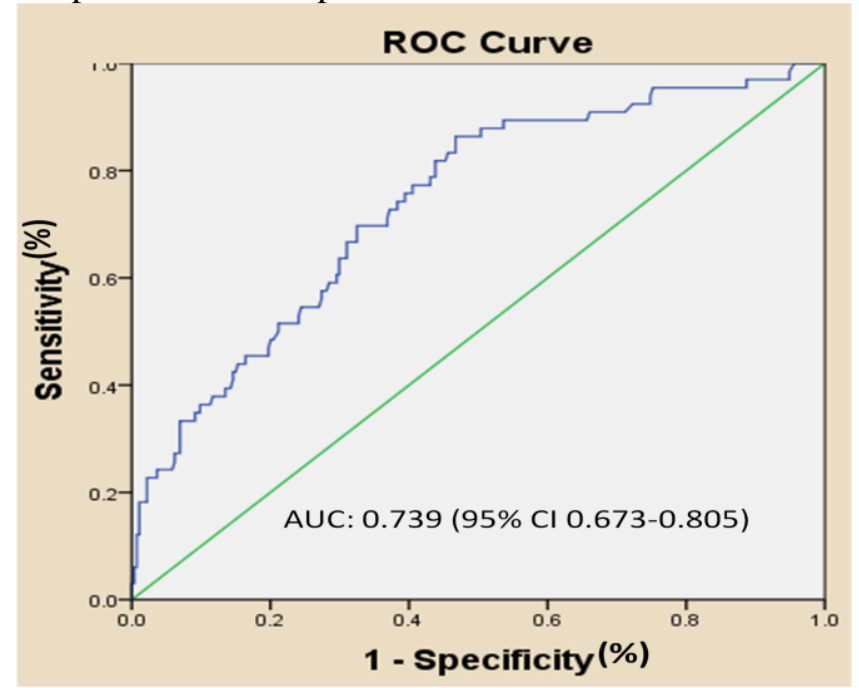

Figure1. Receiver operating characteristic (ROC) curve of the neutrophil-lymphocyte ratio (NLR) for the determination of the optimal cut-off value. The optimal cut-off value of the NLR for the prediction of poor shortterm outcome was 2.135 (sensitivity $86.4 \%$, specificity $53.3 \%$ ).

\subsection{Independent Variables Associated with Poor Functional Outcome}

Multivariate logistic regression analysis demonstrated that age $\geq 65$ years (OR 10.2; 95\% CI 3.31-31.21, $P<0.001$ ), presence of diabetes mellitus (OR 3.3; 95\% CI 1.36-8.18, $P=0.008$ ),
NHISS score at admission $\geq 4$ (OR 26.4; 95\% CI 9.81-71.15, $P<0.001$ ), serum hs-CRP level (OR 1.2; 95\% CI 1.01-1.34, $P=0.041)$, and NLR $\geq 2.135$ (OR 9.2; 95\% CI 3.18-26.4, $P<0.001$ ) were independently associated with poor functional outcome (Table 2).

Table2. Independent predictors of poor outcome in acute ischemic stroke in a multivariate logistic regression analysis.

\begin{tabular}{|l|c|c|c|c|}
\hline \multicolumn{1}{|c|}{ Variables } & $\begin{array}{c}\text { Univariated analysis } \\
\text { OR (95\% CI) }\end{array}$ & $\boldsymbol{P}$-value & $\begin{array}{c}\text { Multivariated analysis } \\
\text { Adjusted OR (95\% CI) }\end{array}$ & $\boldsymbol{P}$-value \\
\hline Age $\geq 65$ years & $11.825(4.944-28.285)$ & $<0.001$ & $10.16(3.31-31.21)$ & $<0.001$ \\
\hline Sex (Female) & $2.028(1.163-3.537)$ & 0.013 & $0.967(0.418-2.236)$ & 0.938 \\
\hline Hypertension & $2.475(1.114-5.496)$ & 0.026 & $1.233(0.388-3.912)$ & 0.723 \\
\hline Diabetes & $1.835(1.054-3.197)$ & 0.032 & $3.339(1.363-8.180)$ & 0.008 \\
\hline Atrial fibrillation & $5.969(3.163-11.265)$ & $<0.001$ & $2.239(0.861-5.821)$ & 0.098 \\
\hline NIHSS score $\geq 4$ & $26.684(1.416-57.402)$ & $<0.001$ & $26.41(9.805-71.15)$ & $<0.001$ \\
\hline Heart rate & $1.02(1.005-1.036)$ & 0.011 & $1.007(0.986-1.029)$ & 0.511 \\
\hline hs-CRP & $1.192(1.052-1.350)$ & 0.006 & $1.161(1.006-1.339)$ & 0.041 \\
\hline CK-MB & $1.148(1.055-1.249)$ & 0.001 & $1.118(0.999-1.251)$ & 0.053 \\
\hline NLR $\geq 2.135$ & $7.168(3.414-15.051)$ & $<0.001$ & $9.158(3.177-26.40)$ & $<0.001$ \\
\hline
\end{tabular}

NIHSS; National Institutes of Health Stroke Scale, hs-CRP; high sensitivity C-reactive protein, CK-MB; creatine kinase-MB, NLR; neutrophil to lymphocyte ratio, OR; odds ratio 


\section{DISCUSSION}

In the present study, we found that a high NLR $(>2.135)$ was associated with poor short-term functional outcome after AIS. Therefore, the NLR may be an effective prognostic predictor of AIS.

Inflammatory processes play an important role in AIS [28]. As inflammatory markers, different subtypes of WBC may have different roles in response to AIS. Previous studies have shown that neutrophil and lymphocyte counts attribute to the inflammatory response and to atherosclerotic processes [29-31]. Cerebral infarction results in liquefaction necrosis through inflammatory processes. These inflammatory cells may exacerbate damage in cerebral infarction by destroying the penumbra [32].

The initial response to an ischemic brain zone is the migration of neutrophils into the damaged area [33]. In physiological conditions, the blood brain barrier (BBB) controls the entry of immune cells into the brain. However, the entry of neutrophils is enhanced by a local BBB breakdown induced by ischemia [12, 34, 35]. Perivascular neutrophil migration into the intraparenchymal area occurs within 6 to 24 hours $[35,36]$. These neutrophils can accumulate in the ischemic and reperfused areas, leading to damage through mediators such as proteolytic enzymes, elastase, arachidonic acid, and free oxygen radicals $[19,20]$. Haumer et al. reported that neutrophil counts $>5,800 / \mu \mathrm{L}$ increased the risk of major cardiovascular events, death, and the composite of myocardial infarction, stroke, and death compared with patients with neutrophil counts $<4,400 / \mu \mathrm{L}$ [37].

Lymphocytes also play a role by regulating immune responses. Lymphocytes are elevated 36 days after stroke in the ischemic brain [38]. Tcell lymphocytes may play an important role in repairing inflamed tissues [39, 40]. This T-cellmediated repair modulates microglial activation through the release of cytokines and growth factors $[39,40]$. Lymphocytes are a prognostic marker for cardiovascular disease but the role of lymphocytes in AIS remains controversial. Some studies have demonstrated that decreased lymphocyte counts are associated with poor functional outcome [10,39].

The NLR is a simple, inexpensive, and readily available inflammatory biomarker. Lately, the NLR has been reported as an independent predictor of the severity and mortality of acute coronary syndrome [17-23]. Several studies have supported the hypothesis that the NLR is an independent factor for predicting short-term mortality and unfavorable functional outcome in AIS [23, 24, 32, 34, 41]. Tokgoz et al. reported that the NLR at the time of hospital admission might be a predictor of short-term mortality independent of infarct volume in patients with AIS [42]. Furthermore, the NLR has been reported to be an independent risk factor for the incidence of AIS in generally healthy populations [2]. In our study, the NLR and the total WBC count were significantly higher in the poor outcome group than in the good outcome group, similar to results reported in other studies [23, 24, 32-34]. This result remains significant even after adjustment for various potential confounders. The damage of the ischemic brain caused by neutrophil infiltration and the release of inflammatory mediators may explain the association of the elevated NLR with poor shortterm functional outcome found in our results.

In our study, the optimal cut-off value of the NLR for predicting unfavorable short-term outcome was 2.135. Multivariate logistic regression analysis demonstrated that an NLR $\geq 2.135$ was independently associated with poor functional outcome. These findings show that the NLR is an independent predicting factor of short-term outcome in AIS. Additionally, age $\geq 65$ years, presence of diabetes mellitus, NHISS score $\geq 4$, and a serum hs-CRP level were also independent predictors of poor functional outcome.

Several studies have attempted to determine the relationship between the NLR and stroke subtype [23, 33, 41, 43, 44]. Most reports have produced consistent results indicating that lacunar stroke is associated with a lower NLR, and that large artery disease is associated with a higher NLR. However, we were unable to propose that the prognostic value of NLR differed according to stroke subtype because stroke subtype was not analyzed in our study.

Theoretically, the inhibition of neutrophils may be beneficial in stroke therapy and has been shown to improve clinical outcome in some experimental models $[12,13]$. Our results also propose that this therapy may be a potential treatment option for AIS. However, clinical studies have found anti-neutrophil therapy to be an ineffective treatment for AIS [14, 15]. Further investigations and better understanding of anti-neutrophil treatment may be needed to improve outcomes in patients with AIS. 
This study had several limitations. First, the sample size was too small to calculate a multivariate analysis using all factors that showed an influence in the univariate analysis. Second, the study design was retrospective, and the data were collected from a single center, both of which may have caused selection bias. Third, our study was based on a single test. Repeated tests during cerebral infarction would be more informative. Finally, although various factors or diseases that might have affected inflammatory markers were excluded, the list of exclusionary factors was not exhaustive.

\section{CONCLUSION}

Our study showed that the NLR is a useful marker for short-term functional outcome in AIS. The NLR may have a role in risk stratification for predicting poor outcome. Further research is required in large prospective cohorts to better understand the dynamic changes in the NLR.

\section{REFERENCES}

[1] Kim JS., Stroke becomes the 3rd important cause of death in Korea; is it a time to toast?, J. Stroke. 16(2), 55-56 (2014).

[2] Suh B., Shin DW., Kwon HM., Yun JM., Yang HK., Ahn E., Lee H., Park JH. and Cho B., Elevated neutrophil to lymphocyte ratio and ischemic stroke risk in generally healthy adults, PLoS. One. 12(8):e0183706 (2017).

[3] Emerging Risk Factors Collaboration., Kaptoge S., Di Angelantonio E., Pennells L., et al., Creactive protein, fibrinogen, and cardiovascular disease prediction, N. Engl. J. Med. 367(14), 1310-1320 (2012).

[4] Fu Y., Liu Q., Anrather J. and Shi FD., Immune interventions in stroke, Nat. Rev. Neurol. 11(9), 524-535 (2015).

[5] Kim JY., Park J., Chang JY., Kim SH. and Lee JE., Inflammation after ischemic stroke: the role of leukocytes and glial cells. Exp. Neurobiol. 25(5), 241-251 (2016).

[6] Barone FC., Hillegass LM., Price WJ., White RF., Lee EV., Feuerstein GZ., Sarau HM., Clark RK. and Griswold DE., Polymorphonuclear leukocyte infiltration into cerebral focal ischemic tissue: myeloperoxidase activity assay and histologic verification, J. Neurosci. Res. 29(3), 336-345 (1991).

[7] Herz J., Sabellek P., Lane TE., Gunzer M., Hermann DM. and Doeppner TR., Role of neutrophils in exacerbation of brain injury after focal cerebral ischemia in hyperlipidemic mice, Stroke. 46(10), 2916-2925 (2015).

[8] Satoh S., Kobayashi T., Hitomi A., Ikegaki I., Suzuki Y., Shibuya M., Yoshida J. and Asano
T., Inhibition of neutrophil migration by a protein kinase inhibitor for the treatment of ischemic brain infarction, Jpn. J. Pharmacol. 80(1), 41-48 (1999).

[9] Matsuo Y., Kihara T., Ikeda M., Ninomiya M., Onodera H. and Kogure K., Role of neutrophils in radical production during ischemia and reperfusion of the rat brain: effect of neutrophil depletion on extracellular ascorbyl radical formation, J. Cereb. Blood. Flow. Metab. 15(6), 941-947 (1995).

[10] Kim J., Song TJ., Park JH., Lee HS., Nam CM., Nam HS., Kim YD. and Heo JH., Different prognostic value of white blood cell subtypes in patients with acute cerebral infarction, Atherosclerosis. 222(2), 464-467 (2012).

[11] Kim J., Song TJ., Park JH., Lee HS., Nam CM., Nam HS., Kim YD. and Heo JH., Different prognostic value of white blood cell subtypes in patients with acute cerebral infarction, Atherosclerosis. 222(2), 464-467 (2012).

[12] Grøgaard B., Schürer L., Gerdin B. and Arfors KE., Delayed hypoperfusion after incomplete forebrain ischemia in the rat. The role of polymorphonuclear leukocytes, J. Cereb. Blood. Flow. Metab. 9(4), 500-505 (1989).

[13] Easton AS., Neutrophils and stroke - can neutrophils mitigate disease in the central nervous system? Int. Immunopharmacol. 17(4), 1218-1225 (2013).

[14] Krams M., Lees KR., Hacke W., Grieve AP., Orgogozo JM. and Ford GA; ASTIN Study Investigators, Acute Stroke Therapy by Inhibition of Neutrophils (ASTIN): an adaptive dose-response study of UK-279,276 in acute ischemic stroke, Stroke. 34(11), 2543-2548 (2003).

[15] Enlimomab Acute Stroke Trial Investigators., Use of anti-ICAM-1 therapy in ischemic stroke: results of the Enlimomab Acute Stroke Trial, Neurology. 57(8), 1428-1434 (2001).

[16] Zahorec R., Ratio of neutrophil to lymphocyte counts-rapid and simple parameter of systemic inflammation and stress in critically ill, Bratisl. Lek. Listy. 102(1), 5-14 (2001).

[17] Tamhane UU., Aneja S., Montgomery D., Rogers EK., Eagle KA. and Gurm HS., Association between admission neutrophil to lymphocyte ratio and outcomes in patients with acute coronary syndrome, Am. J. Cardiol. 102(6), 653-657 (2008).

[18] Shen XH., Chen Q., Shi Y. and Li HW., Association of neutrophil/lymphocyte ratio with long-term mortality after ST elevation myocardial infarction treated with primary percutaneous coronary intervention, Chin. Med. J. 123(23), 3438-3443 (2010). 
[19] Azab B., Zaher M., Weiserbs KF., Torbey E., Lacossiere K., Gaddam S., Gobunsuy R., Jadonath S., Baldari D., McCord D. and Lafferty J., Usefulness of neutrophil to lymphocyte ratio in predicting short- and longterm mortality after non-ST-elevation myocardial infarction, Am. J. Cardiol. 106(4), 470-476 (2010).

[20] Muhmmed Suliman MA., Bahnacy Juma AA., Ali Almadhani AA., Pathare AV., Alkindi SS. and Uwe Werner F., Predictive value of neutrophil to lymphocyte ratio in outcomes of patients with acute coronary syndrome, Arch. Med. Res. 41(8), 618-622 (2010).

[21] Papa A., Emdin M., Passino C., Michelassi C., Battaglia D. and Cocci F., Predictive value of elevated neutrophil-lymphocyte ratio on cardiac mortality in patients with stable coronary artery disease, Clin. Chim. Acta. 395(1-2), 27-31 (2008).

[22] Arbel Y., Finkelstein A., Halkin A., Birati EY., Revivo M., Zuzut M., Shevach A., Berliner S., Herz I., Keren G. and Banai S., Neutrophil/lymphocyte ratio is related to the severity of coronary artery disease and clinical outcome in patients undergoing angiography, Atherosclerosis. 225(2), 456-460 (2012).

[23] Celikbilek A., Ismailogullari S. and Zararsiz G., Neutrophil to lymphocyte ratio predicts poor prognosis in ischemic cerebrovascular disease, J. Clin. Lab. Anal. 28(1), 27-31 (2014).

[24] Qun S., Tang Y., Sun J., Liu Z., Wu J., Zhang J., Guo J., Xu Z., Zhang D., Chen Z., Hu F., Xu $\mathrm{X}$. and Ge W., Neutrophil-to-lymphocyte ratio predicts 3-month outcome of acute ischemic stroke, Neurotox. Res. 31(3), 444-452 (2017).

[25] Sulter G., Steen C. and De Keyser J., Use of the Barthel index and modified Rankin scale in acute stroke trials, Stroke. 30(8), 1538-1541 (1999).

[26] Brott TG., Adams HP., Olinger CP., Marler JR., Barsan WG., Biller J., Spilker J., Holleran R., Eberle R., Hertzberg V., Rorick M., Moomaw CJ. and Walker M., Measurements of acute cerebral infarction: a clinical examination scale, Stroke. 20(7), 864-870 (1989).

[27] Ho KK., Pinsky JL., Kannel WB. and Levy D., The epidemiology of heart failure: the Framingham Study, J. Am. Coll. Cardiol. 22(4 Suppl A), 6A-13A (1993).

[28] Chamorro A. and Hallenbeck J., The harms and benefits of inflammatory and immune responses in vascular disease, Stroke. 37(2), 291-293 (2006).

[29] Ait-Oufella H., Salomon BL., Potteaux S., Robertson AK., Gourdy P., Zoll J., Merval R., Esposito B., Cohen JL., Fisson S., Flavell RA.,
Hansson GK., Klatzmann D., Tedqui A. and Mallat Z., Natural regulatory T cells control the development of atherosclerosis in mice, Nat. Med. 12(2), 178-180, (2006).

[30] Gupta S., Agrawal A., Agrawal S., Su H. and Gollapudi S., A paradox of immunodeficiency and inflammation in human aging: lessons learned from apoptosis, Immun. Ageing. 3:5 (2006).

[31] Nasr N., Ruidavets JB., Arnal JF., Sie P. and Larrue V., Association of neutrophil count with microembolization in patients with symptomatic carotid artery stenosis, Atherosclerosis. 207(2), 519-523 (2009).

[32] Tokgoz S., Kayrak M., Akpinar Z., Seyithanoğlu A., Güney F. and Yürüten B., Neutrophil lymphocyte ratio as a predictor of stroke, J. Stroke. Cerebrovasc. Dis. 22(7), 1169-1174 (2013).

[33] Buck BH., Liebeskind DS., Saver JL., Bang OY., Yun SW., Starkman S., Ali LK., Kim D., Villablanca JP., Salamon N., Razinia T. and Ovbiagele B., Early neutrophilia is associated with volume of ischemic tissue in acute stroke, Stroke. 39(2), 355-360 (2008).

[34] Xue J., Huang W., Chen X., Li Q., Cai Z., Yu T. and Shao B., Neutrophil-to-lymphocyte ratio is a prognostic marker in acute ischemic stroke, J. Stroke. Cerebrovasc. Dis. 26(3), 650-657 (2017).

[35] Garcia JH., Liu KF., Yoshida Y., Lian J., Chen S. and del Zoppo GJ., Influx of leukocytes and platelets in an evolving brain infarct (Wistar rat), Am. J. Pathol. 144(1), 188-199 (1994).

[36] Clark RK., Lee EV., White RF., Jonak ZL., Feuerstein GZ. and Barone FC., Reperfusion following focal stroke hastens inflammation and resolution of ischemic injured tissue, Brain. Res. Bull. 35(4), 387-392 (1994).

[37] Haumer M., Amighi J., Exner M., Mlekusch W., Sabeti S., Schlager O., Schwarzinger I., Wagner O., Minar E. and Schillinger M., Association of neutrophils and future cardiovascular events in patients with peripheral artery disease, J. Vasc. Surg. 41(4), 610-617 (2005)

[38] Li GZ., Zhong D., Yang LM., Sun B., Zhong ZH., Yin YH., Cheng J., Yan BB. and Li HL., Expression of interleukin-17 in ischemic brain tissue, Scand. J. Immunol. 62(5), 481-486 (2005).

[39] Schwartz M. and Moalem G., Beneficial immune activity after CNS injury: prospects for vaccination, J. Neuroimmunol. 113(2), 185-192 (2001).

[40] Palm NW. and Medzhitov R., Not so fast: adaptive suppression of innate immunity, Nat. Med. 13(10), 1142-1144 (2007). 
[41] Gokhan S., Ozhasenekler A., Mansur Durgun H., Akil E., Ustündag M. and Orak M., Neutrophil lymphocyte ratios in stroke subtypes and transient ischemic attack, Eur. Rev. Med. Pharmacol. Sci. 17(5), 653-657 (2013).

[42] Tokgoz S., Keskin S., Kayrak M., Seyithanoglu A. and Ogmegul A., Is neutrophil/lymphocyte ratio predict to short-term mortality in acute cerebral infarct independently from infarct volume?, J. Stroke. Cerebrovasc. Dis. 23(8),
2163-2168 (2014).

[43] Rodríguez-Yáñez M. and Castillo J., Role of inflammatory markers in brain ischemia, Curr. Opin. Neurol. 21(3), 353-357 (2008).

[44] Elkind MS., Sciacca RR., Boden-Albala B., Rundek T., Paik MC. and Sacco RL., Relative elevation in baseline leukocyte count predicts first cerebral infarction, Neurology. 64(12), 2121-2125 (2005).

Citation: Meyung Kug Kim, Jin Hyung Lee, Bong Goo Yoo. Neutrophil to Lymphocyte Ratio Predicts ShortTerm Functional Outcome in Acute Ischemic Stroke. ARC Journal of Neuroscience. 2017; 2(3):29-37. doi:dx.doi.org/10.20431/2456-057X.0203005.

Copyright: (C) 2017 Authors. This is an open-access article distributed under the terms of the Creative Commons Attribution License, which permits unrestricted use, distribution, and reproduction in any medium, provided the original author and source are credited. 